tion. When more than one cell is to be used at a time they can all be worked in unison by running a wooden rod through the rings by which the springs are attached to the zincs.

Cells of the type here described are, perhaps, even more valuable in the laboratory than in the lecture room. For fairly strong currents they are about as steady as copper sulphate-batteries, and enormously cheaper and less troublesome, and wherever the extreme steadiness of the storage or Edison battery is not demanded their convenience and low cost of maintenance have made them, in the writer's opinion and experience, the best battery for most high school laboratory work.

\title{
AN EXPERIMENT TO DEMONSTRATE THAT THE PULSE IS CAUSED BY A WAVE OF PRESSURE AND IS NOT DUE TO THE ONWARD FLOW OF THE BLOOD.
}

\author{
By S. D. Magers, M. S. \\ State Normal College, Ypsilanti, Mich.
}

To demonstrate that the pulse is due to a wave of pressure and not to the onward flow of the blood, these two facts must be understood by the student: First, that the tension of the walls of the arteries makes their contained blood fill them completely. Second, that with each ventricular systole, about five ounces of blood are forced into the already filled aorta.

To show that this influx of blood causes increased pressure on the walls of the aorta at its base and that this starts a wave of pressure traveling with great rapidity toward the capillaries, causing an expansion of the arteries in its course, a pulse wave, the following apparatus is devised: A drum kymograph, two time-markers, a rubber tube with syringe bulb at one end, a jar of water and two pulse recording levers.

The kymograph of the type shown in the illustration has the paper of its drum smoked, the drum making nearly four revolutions per minute. The seconds time marker, making the lowest line (4), is controlled by a pendulum, within an electric circuit, vibrating through a drop of mercury to make and break the circuit at second intervals. The other time marker, making the uppermost line (1), consists of a tuning fork, also within an 

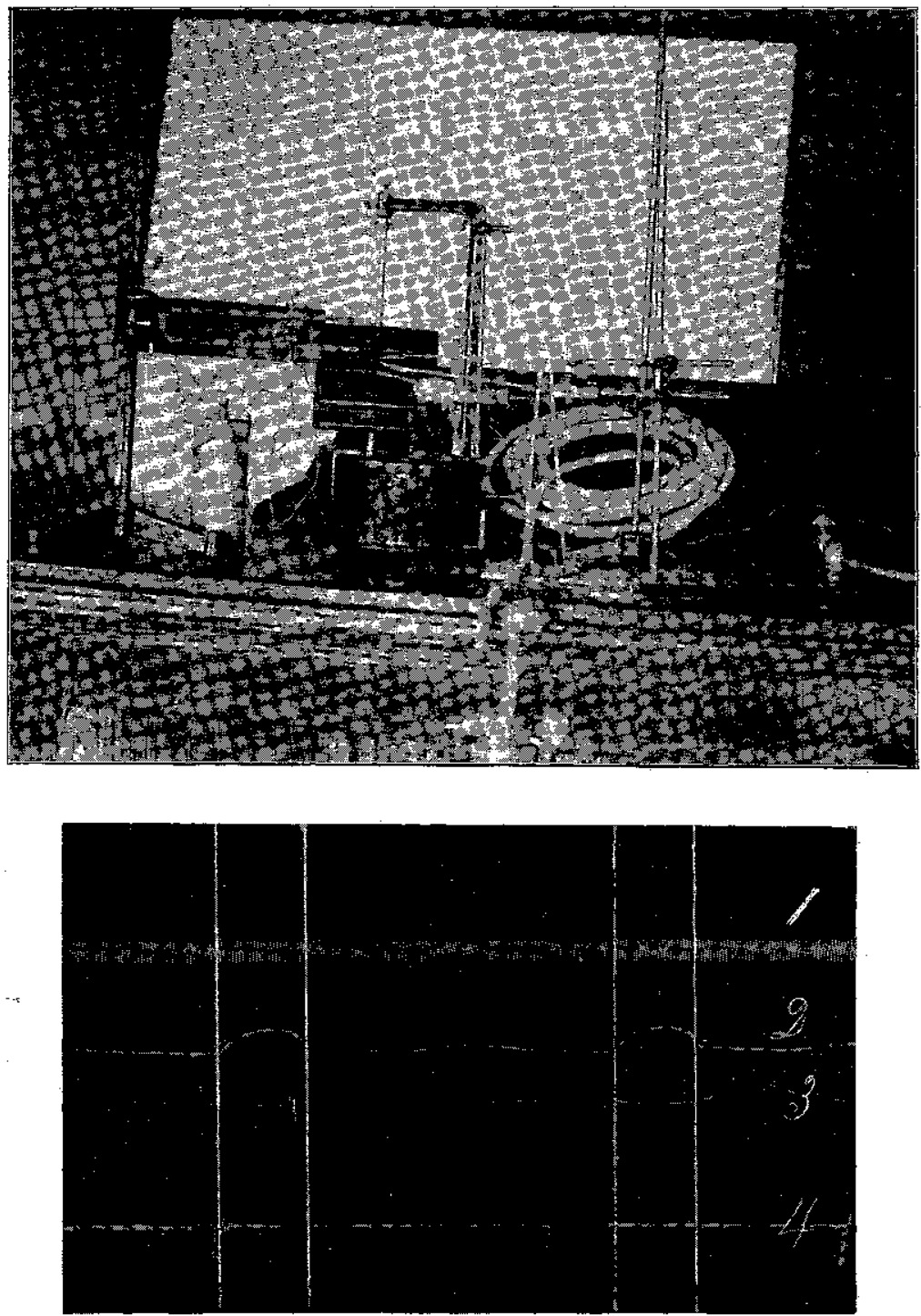

electric circuit, vibrating one hundred times per second, so adjusted that one arm with a thin, sharp pointed spring records one-hundredth seconds on the drum. The rubber tube, twentyfive feet in length, a half inch in diameter, coiled to take up less room, has at one end a syringe bulb provided with two valves, 
representing the ventricle, for pumping water into tube from the jar. The distal end of the tube is partially plugged. This permits the water to escape so slowly that when it is pumped into the tube by means of the bulb, the tube is kept full, and pressure is exerted upon its sides.

Two levers with paper pens for recording on the drum were supported by beams resting on the rubber tube, the one at the buib end making line (2) and the other on the distal end making line (3).

Under these conditions, with each compression of the bulb a

(1) Line made by $1 / 100$ seconds time-marker.

(2) Line made by lever resting on bulb end of tube.

(3) Line made by lever resting on the distal end of tube.

(4) Line made by seconds time-marker.

given amount of water is added to the already filled tube, starting a wave of pressure at the bulb, traveling to the distal end of the tube, expanding it in its course.

TO SHOW THE VELOCITY OF THE WAVE.

By placing the tip ends of the pens of the two levers and that of the one-hundred seconds time-marker in a vertical line against the rotating drum, the time elapsing between the beginning of the expansion at the bulb end and the beginning of the expansion at the distal end is recorded in one-hundredth seconds. It will be observed that the line (2), made by the lever whose support rests upon the bulb end begins to rise only about twenty-four hundredths (24-100) of a second befnre the lever resting upon the distal end of the tube, making line (3), showing that the wave travels nearly twenty-five feet in twenty-four hundredths of a second.

TO SHOW THE VELOCITY OF THE BLOOD.

Some eosin solution is injected into the rubber tube at the bulb end by a hypodermic syringe at a time a hard compression of the bulb is made. (The strong compression being made to cause the levers to rise unusually high to indicate the time of the injection). The bulb is compressed regularly and evenly thereafter. It is found that it takes about thirty-five seconds for the eosin to reach the distal end of the tube. Thus demonstrating that before the eosin reaches the distal end of the tube 145 pulse waves have passed over the full length of the tube. That while the eosin travels five-sevenths of a foot per second the 
pulse wave travels ro 4 feet per second. Thus demonstrating that the pulse is a rapidly moving wave of pressure, while the blood lags far behind.

It might be added that these facts may be demonstrated quite clearly without the use of kymograph or time-markers by simply observing the almost synchronous movement of the levers and the long time elapsing between the injection and the outpour of the eosine.

The next person to hold the Rhodes scholarship from Illinois is $\mathrm{Mr}$. Newton Ensign, of McKendree College. He will take the honour course in mathematics at Oxford. Mr. Newton was prepared very largely for this scholarship by Prof. G. W. Greenwood, of McKendree College.

\section{A CORRECTION.}

In the article by William H. Snyder on "Map Construction" there is a mistake in the construction of figure 3 on page 33 of the current volume of this journal. The line A D should pass through the point $K$; that is, there should be one more line drawn from the point A. The tangent line B D is divided into nine parts, the same as the quadrant W. S. The mistake was made by the draughtsman who prepared the drawings for the engraver and is one for which neither Mr. Snyder nor the present editor of the section is responsible.

\section{NOTES FROM THE UNIVERSITY OF ILLINOIS.}

Dr. A. T. Lincoln, assistant professor of chemistry, addressed the Mathematical Club on April 15 upon "Some Applications of Mathematics to Chemical Statics and Dynamics."

Mr. Lewis Omer, '02, instructor in mathematics in the Oak Park Township High School, on April 29, presented to the Mathematical Club a paper on "The Problems of the Young Teacher." Mr. Omer ranks among the best teachers of sccondary mathematics in the state and his discussion of the problems which he had met in his own experience proved him a forcible, level-headed enthusiast in his subject with an appreciation of the difficulties of his students.

Prof. A. N. Talbot, professor of municipal and sanitary engineering, on May 2, presented to the society of Sigma Xi a paper on "Reinforced Concrete." The results of Prof. Talbot's recent investigations on reinforced concrete have been published in "Bulletin No. 1 of the University of Illinois Engineering Experiment Station."

Mr. H. W. Reddick has been appointed fellow in mathematics for next year. Mr. Reddick is a graduate of the Indiana University and for the past year has been instructor in mathematics in the University of Illinois Academy.

ERNEST B. LytLe. 